\title{
Einkaufen
}

\section{Ei ei}

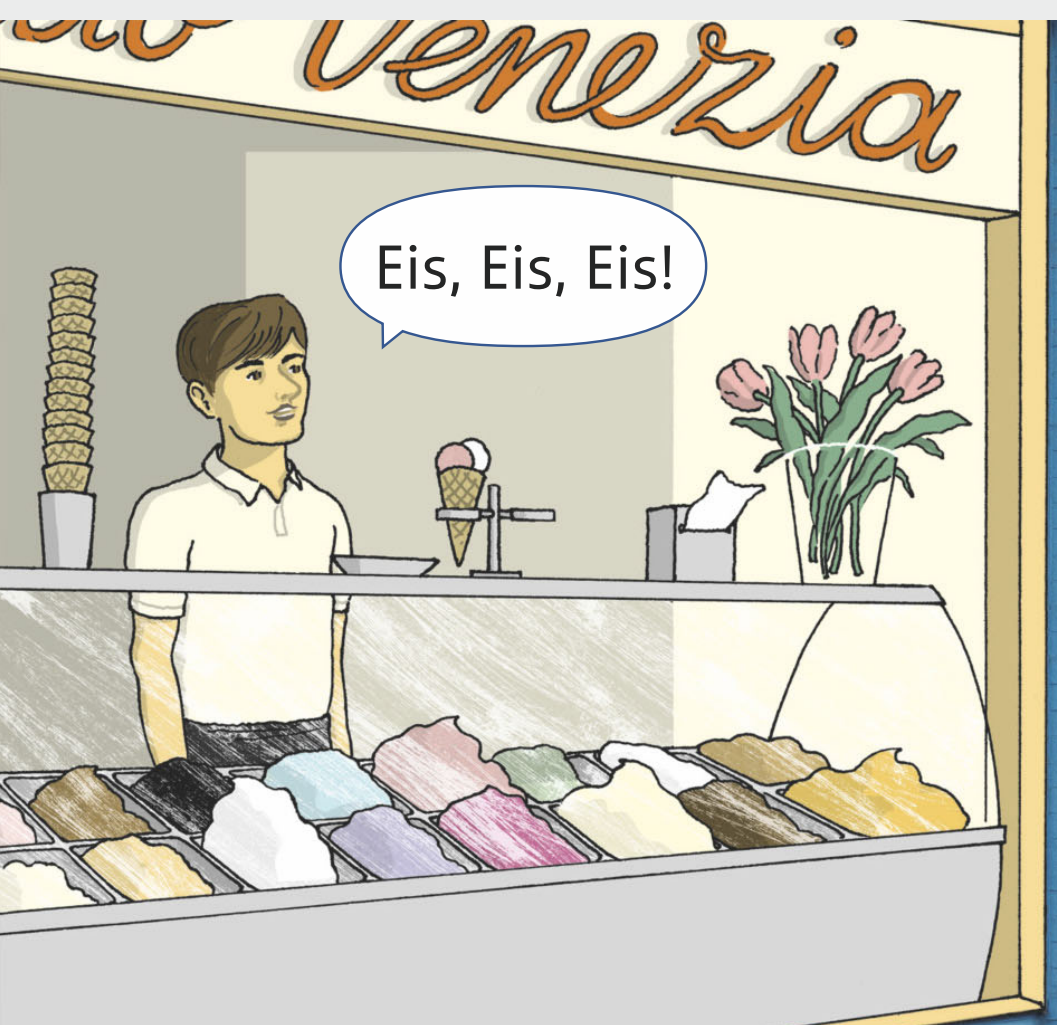




\section{Einkaufen}

3a Sprich und fahre mit dem Finger nach. (3) (1) 8

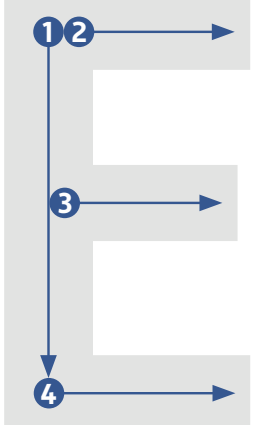

2

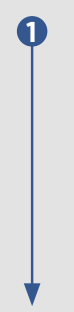

2

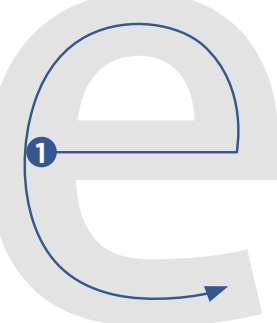

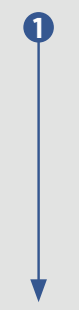

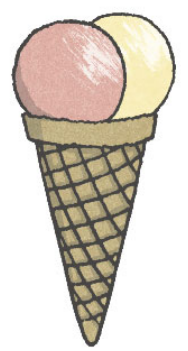

3b Schreibe.

$\mathrm{Ei}$

ei

Ei ei

das Eis

4a Sprich ohne Ton A, E, I oder Ei. Ratet. Dann Wechsel.
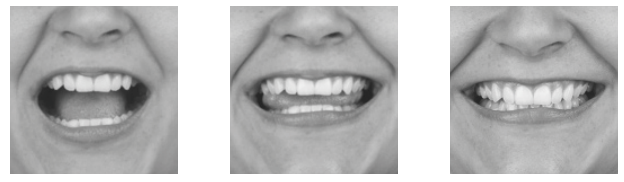

centers

4b Lies und markiere ei. 目

mei

mein

meine dei

dein

deine sei

sein

seine 


\section{Ei ei}

5a Höre und sprich nach. (2) (9, 9
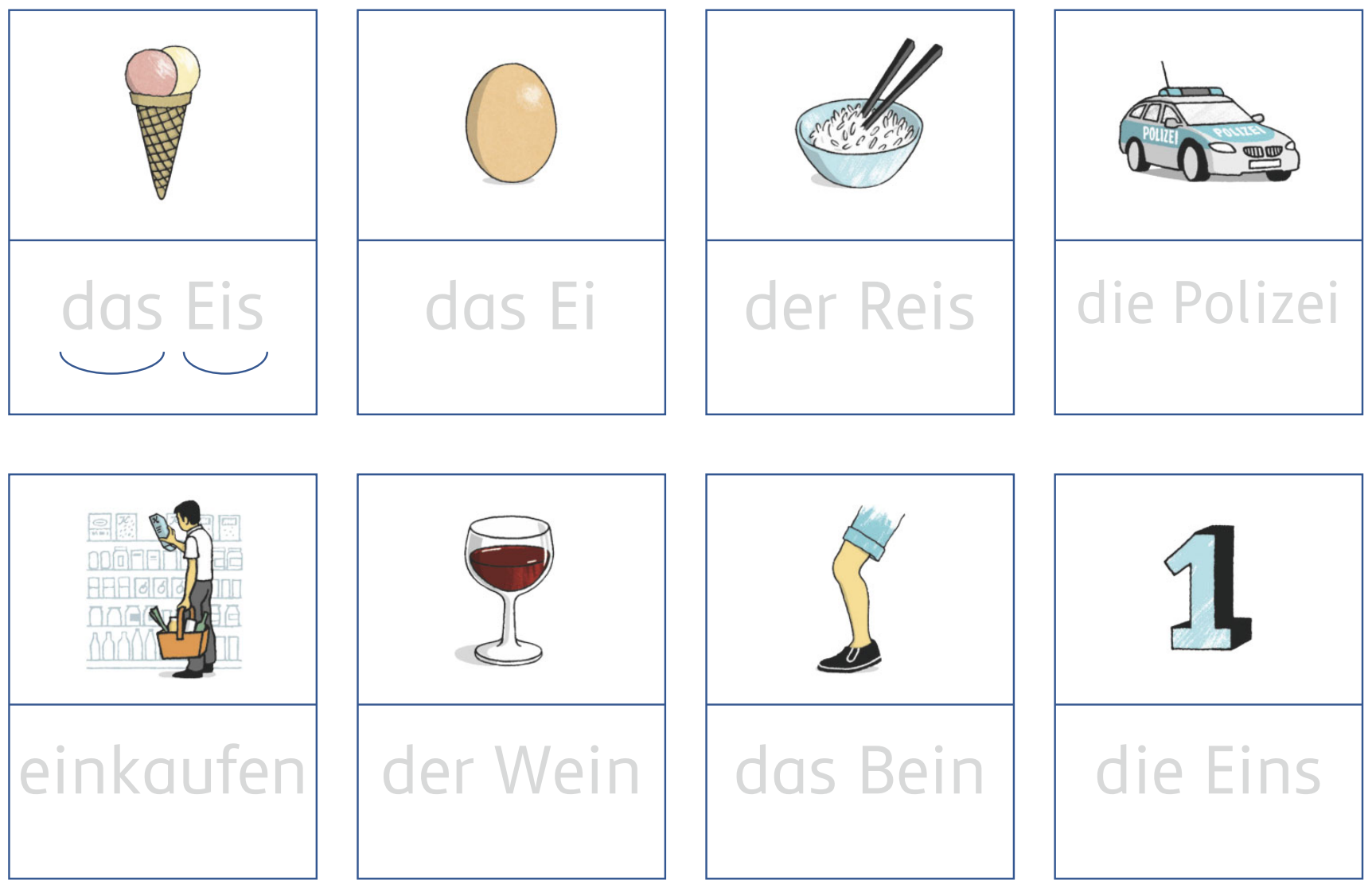

5b Zeichne die Silbenbögen ein.

5c Schreibe Ei ei oder das ganze Wort nach.

6 Spiel. Macht mit. $8 \rightarrow$

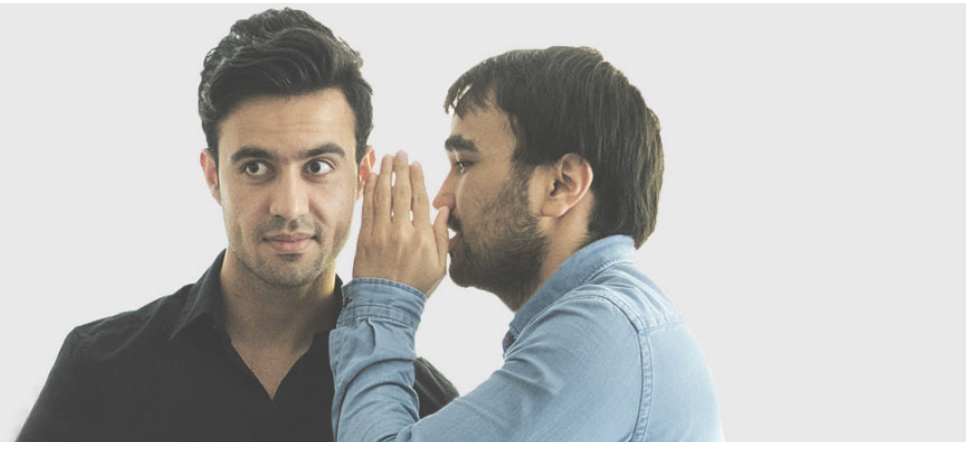

Sitzt im Kreis. Flüstert euch Wörter ins Ohr.

Ist es am Ende richtig? 


\section{Einkaufen}

7a Lies und schreibe. 国

\section{essen}

\section{ich esse}

du isst

\section{wir essen}

trinken

ich trinke

du trinkst

wir trinken

7b Lies und schreibe. 目

I. Ich

(1)

ชี Wir

ํำ
Du

Ich
Eis. P

Pizza.

Tee.

Cola.

7c Haltet zwei Karten hoch und sprecht.

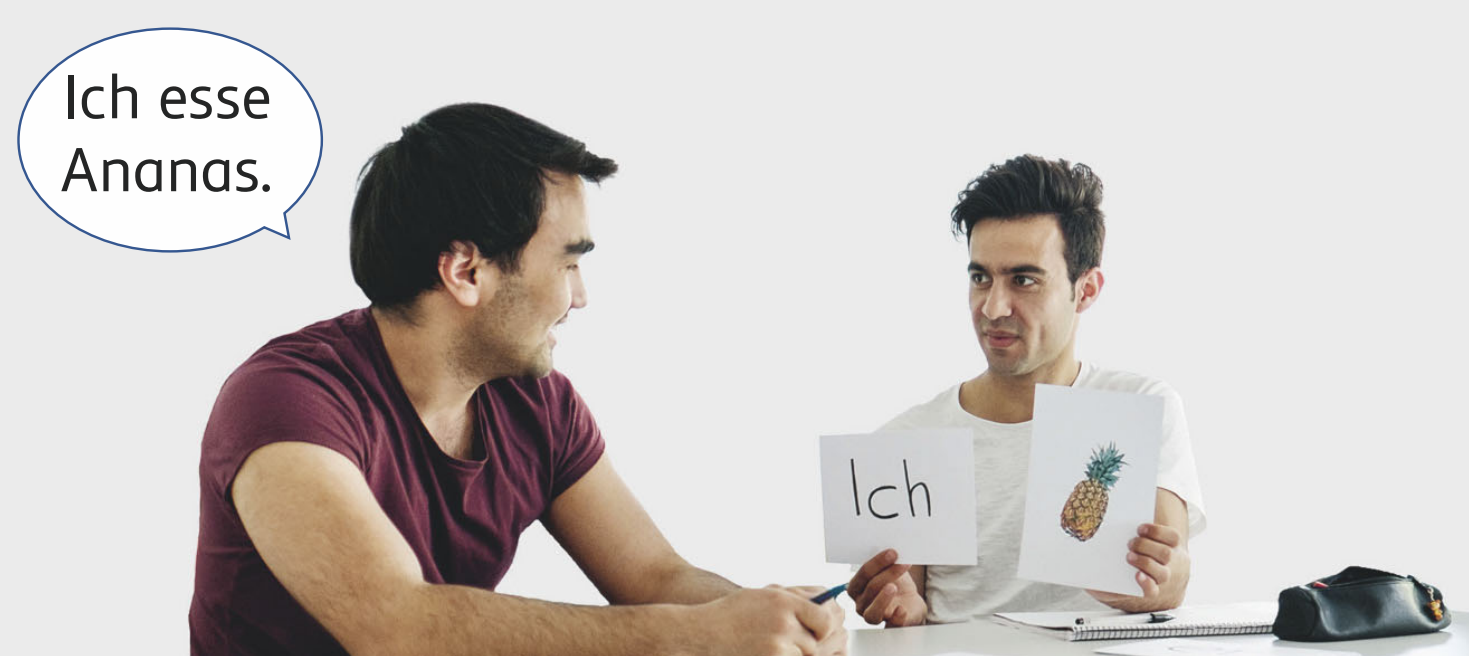




\section{Ei ei}

8a Höre und schreibe. (2) $9{ }_{10}$
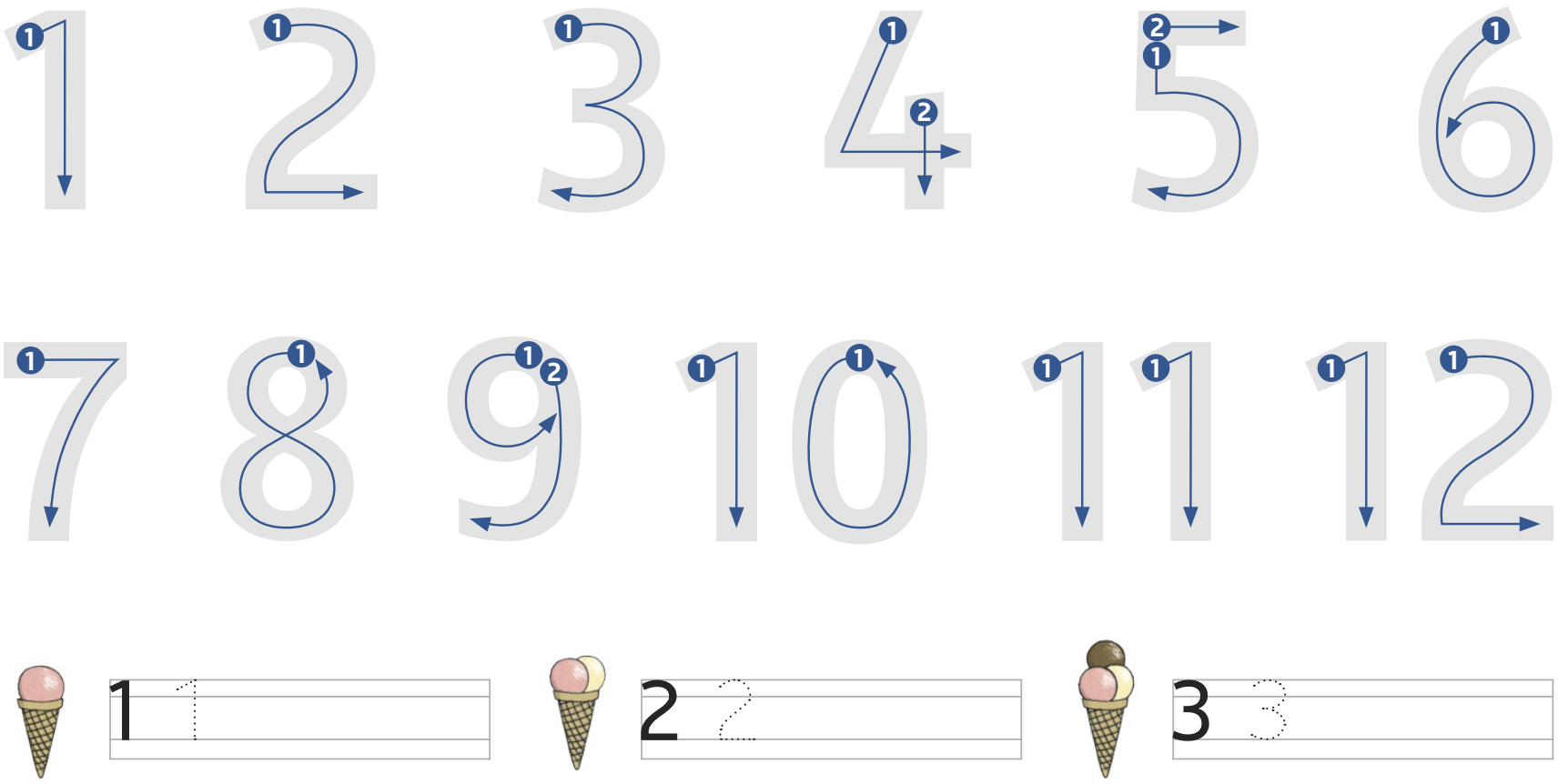

$\nabla 2$
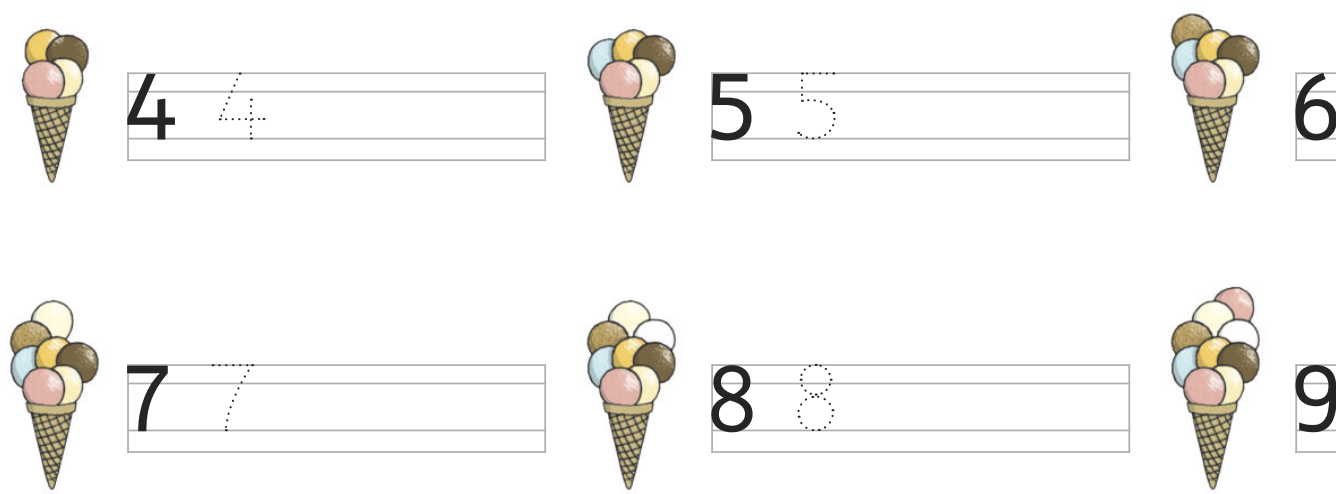

8

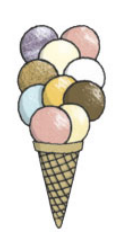

\section{0}
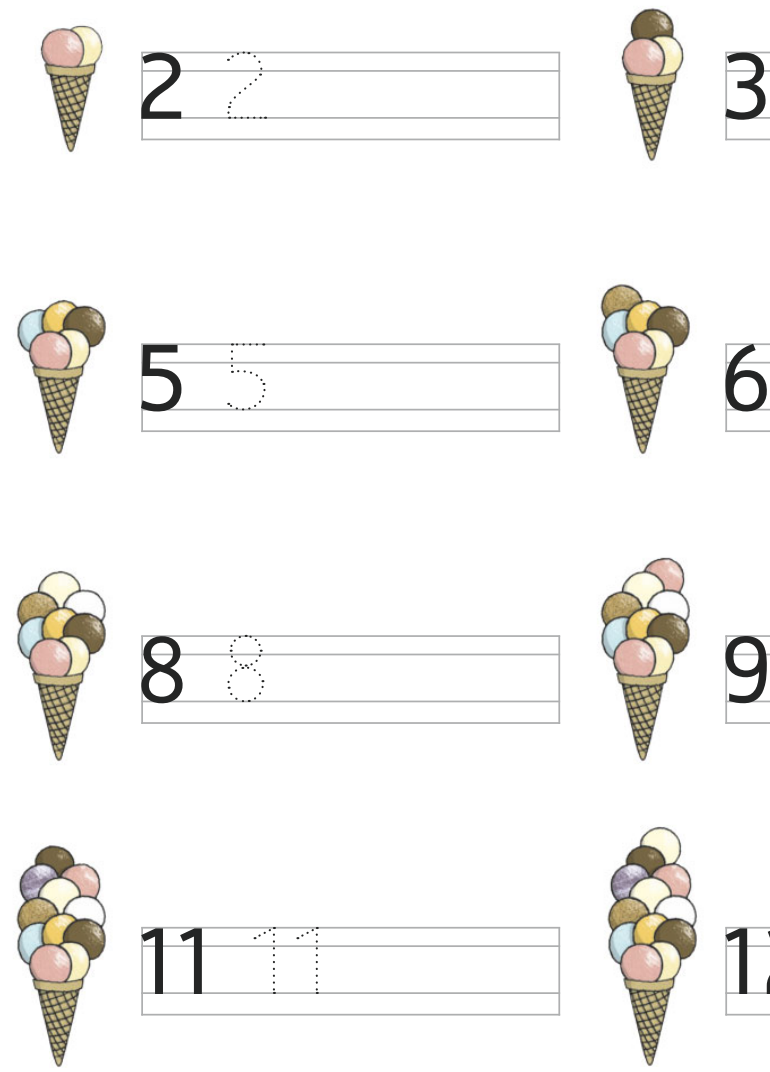

6
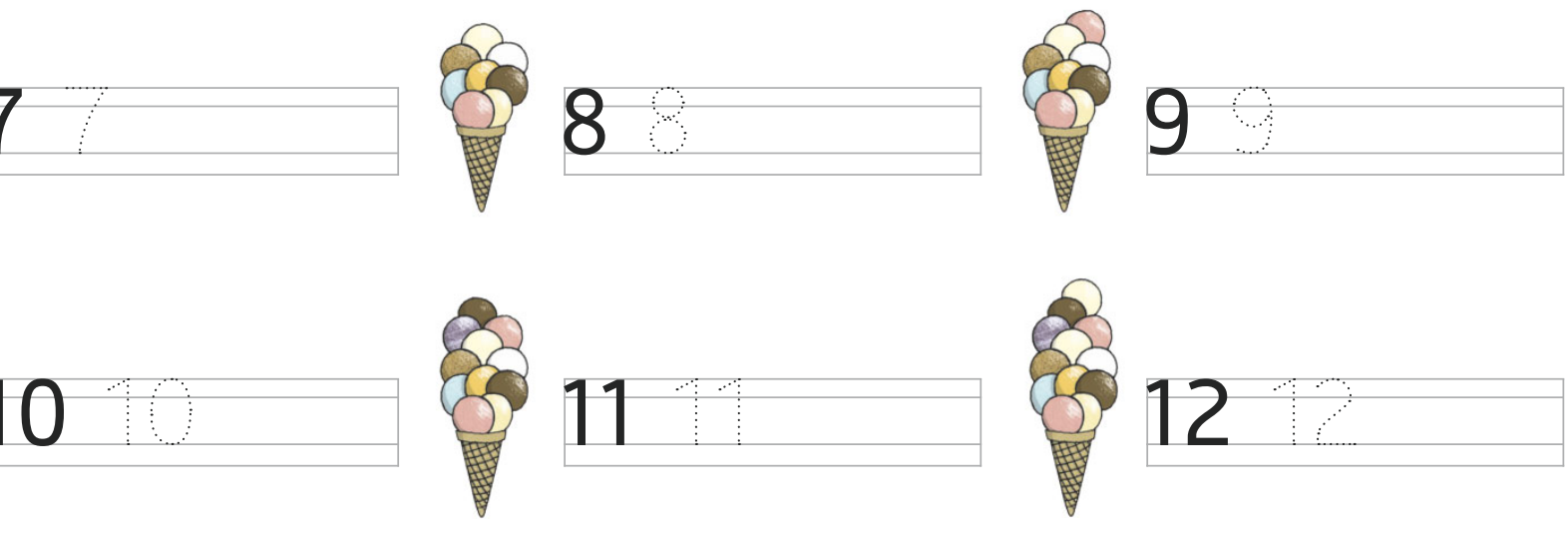

8b Lies und schreibe. 国

eins

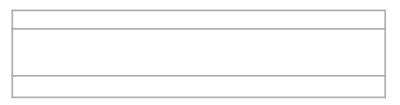

\section{zwei}

drei

$$
\begin{aligned}
& 0=\text { null } \\
& 1=\text { eins } \\
& 2 \text { = zwei } \\
& 3=\text { drei } \\
& 4=\text { vier } \\
& 11=\text { elf } \\
& 5=\text { fünf } \\
& 6=\text { sechs } \\
& 12=\text { zwölf }
\end{aligned}
$$

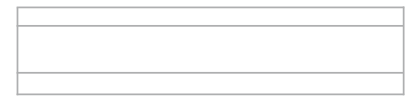




\section{Einkaufen}

9a Höre und sprich nach. (3) (1)
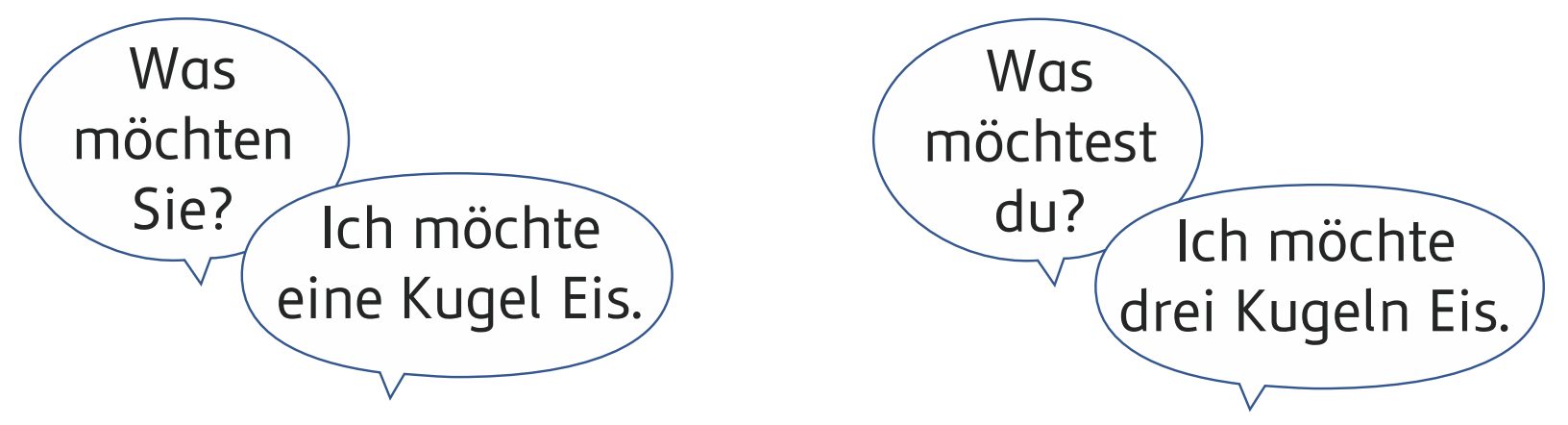

9b Wie viele Kugeln Eis? Höre und male. (2)

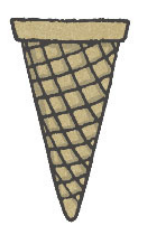

(1)

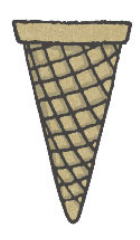

(2)

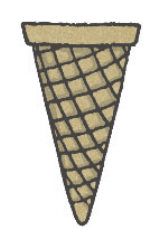

3

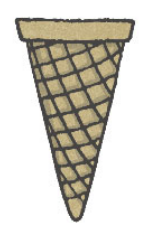

4

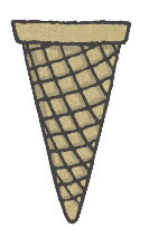

(5)

9c Sprecht zusammen. (-)

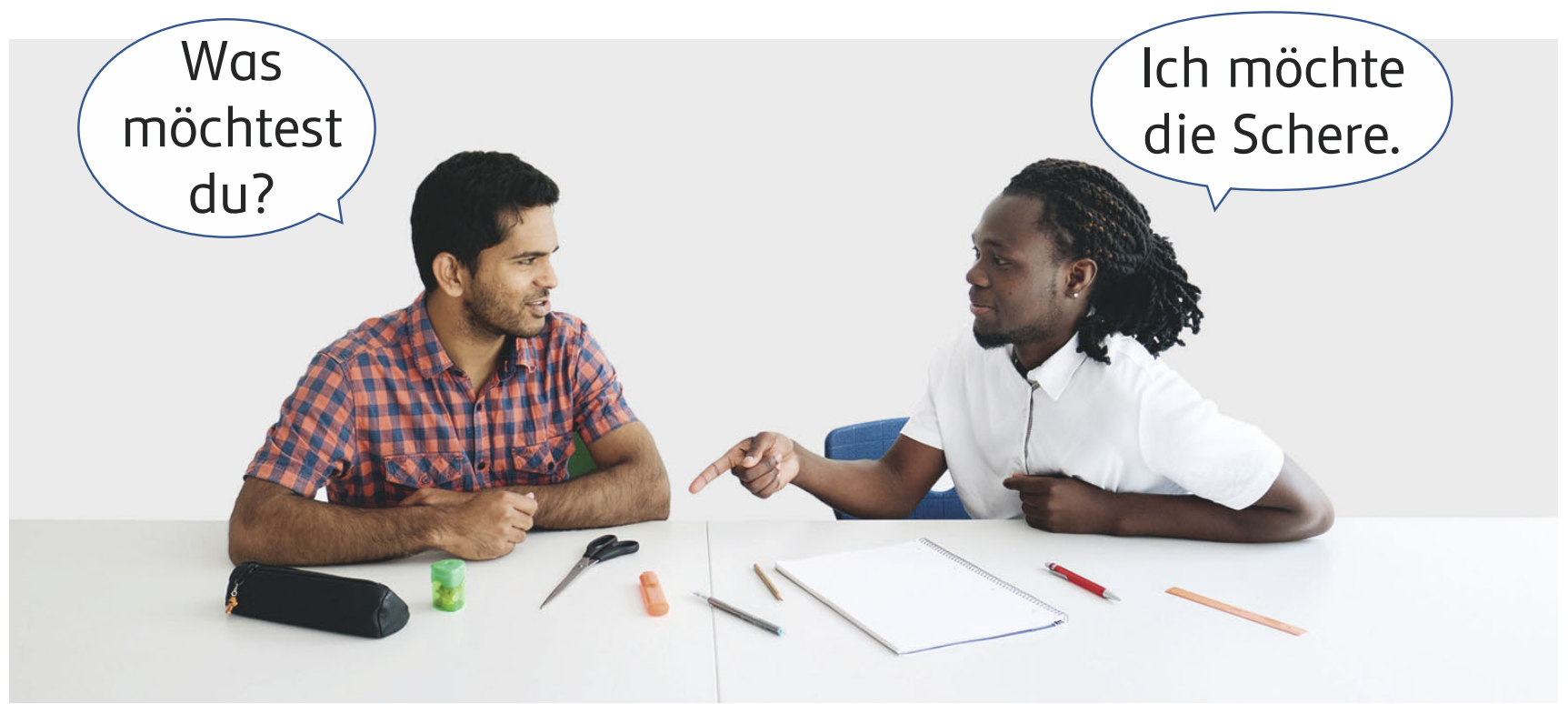




\section{Ei ei}

10a Höre und lies mit. (2) (1) 13 国

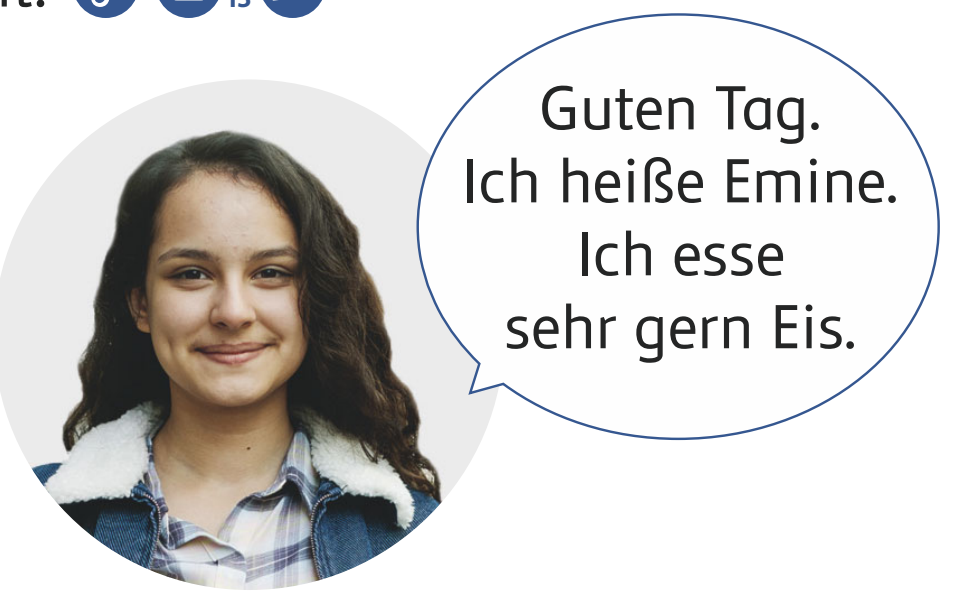

10b Meine Aufgabe für dich. Trenne die Wörter und schreibe neu.

MausElefantSonneDose Ananasinsel Nase RegenSchalEis die Maus

10c Schreibe eine eigene Aufgabe. 
$\star$ Was ist gleich? Verbinde.
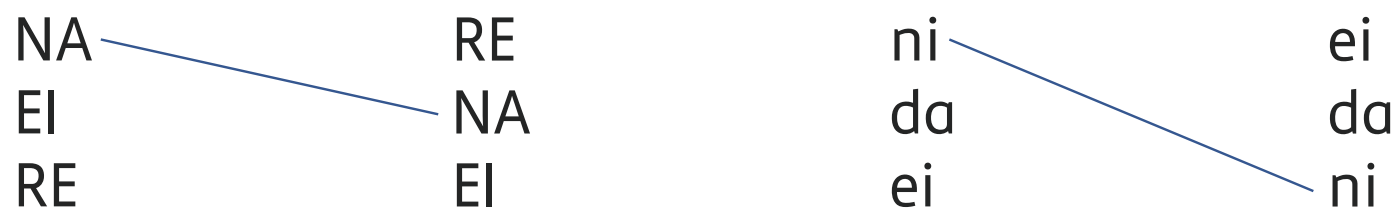

$\star \star$ Schreibe die Zahlen.

1 eins

3

5

7

9
2

4

6

8

10

$\star \star \star$ Essen oder Trinken? Sortiere die Wörter.

der Salat der Tee die Mango

die Milch die Limo

das Eis die Melone

der Kaffee

\begin{tabular}{|c|c|}
\hline Essen & Trinken \\
\hline & \\
\hline & \\
\hline & \\
\hline & \\
\hline
\end{tabular}




\section{Ei ei}

$\star$ Markiere Ei ei.

die Paprika

das Eis

die Polizei leise

die Suppe

vier der Eimer

einkaufen

die Türkei die Zeitung der Mann sieben

$\star \star$ E e oder ei? Schreibe.
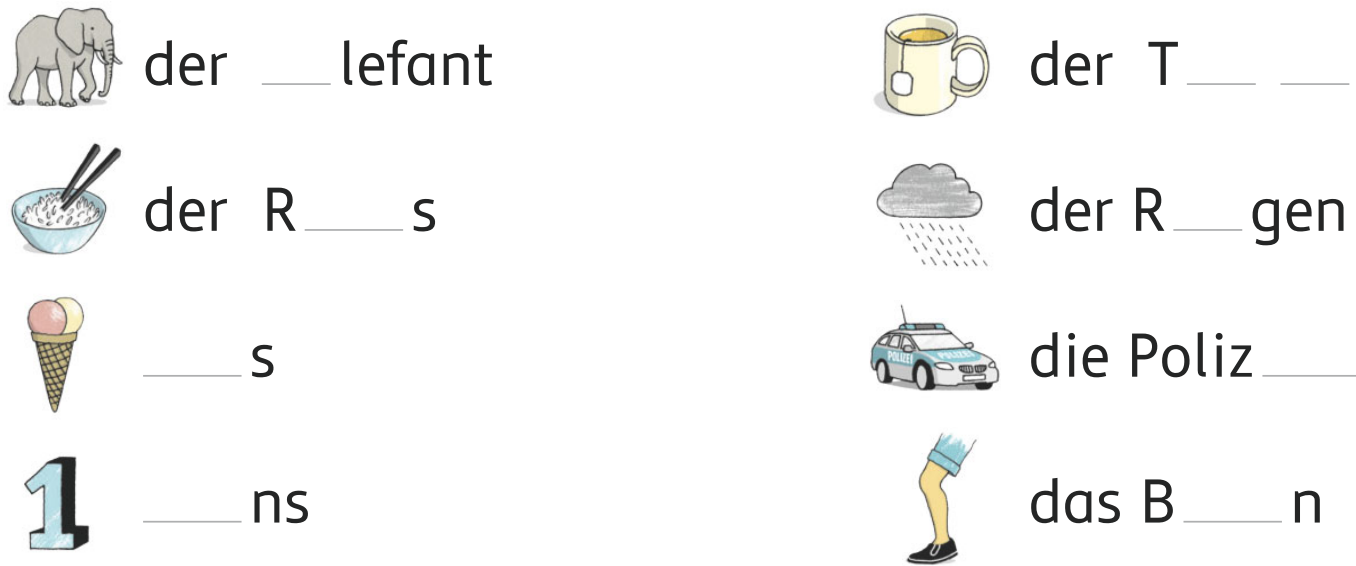

die Poliz das B_n

$\star \star \star$ Schreibe Wörter mit ei. 
圈 Mein Wortschatz

Schreibe.

das Bein

das Ei

das Eis

der Reis

der Wein

einkaufen

essen

trinken

0 null

7 sieben

1 eins

8 acht

2 zwei

9 neun

3 drei

10 zehn

4 vier

11 elf

5 fünf

12 zwölf

6 sechs 
Kombiniere die Sätze.

Was

möchtest

$\mathrm{du}$ ?

Was

möchten

Sie?

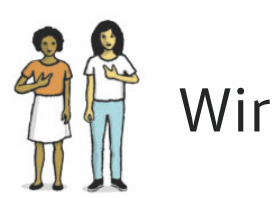

möchte

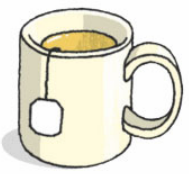

möchten

Open Access Dieses Kapitel wird unter der Creative Commons Namensnennung - Nicht kommerziell - Keine Bearbeitung 4.0 International Lizenz (http://creativecommons.org/licenses/by-nc-nd/4.0/deed.de) veröffentlicht, welche die nicht-kommerzielle Nutzung, Vervielfältigung, Verbreitung und Wiedergabe in jeglichem Medium und Format erlaubt, sofern Sie den/die ursprünglichen Autor(en) und die Quelle ordnungsgemäß nennen, einen Link zur Creative Commons Lizenz beifügen und angeben, ob Änderungen vorgenommen wurden. Die Lizenz gibt Ihnen nicht das Recht, bearbeitete oder sonst wie umgestaltete Fassungen dieses Werkes zu verbreiten oder öffentlich wiederzugeben.

Die in diesem Kapitel enthaltenen Bilder und sonstiges Drittmaterial unterliegen ebenfalls der genannten Creative Commons Lizenz, sofern sich aus der Abbildungslegende nichts anderes ergibt. Sofern das betreffende Material nicht unter der genannten Creative Commons Lizenz steht und die betreffende Handlung nicht nach gesetzlichen Vorschriften erlaubt ist, ist auch für die oben aufgeführten nicht-kommerziellen Weiterverwendungen des Materials die Einwilligung des jeweiligen Rechteinhabers einzuholen. 